\title{
乙 型肝炎抗原的分离
}

\section{察宜权 洪世雯 张立人 陈丽德}

（湖北省微生物研究所病毒室）

李荫 宇

（第一冶金建设公司职工医院检验科）

1964 年, Blumberg ${ }^{[1]}$ 首先在一名澳大利 亚世居居民的血液中发现一种物质，并名之 为澳大利亚抗原 (Australia antigen). 其后, Prince ${ }^{[2]}$ 在乙型肝炎患者血清中观察到类似 的物质而称其为血清性肝炎抗原(Serum hepatitis antigen). 此后不久, 确认这两种物质是 相同的并且和乙型肝炎相关 ${ }^{[3]}$. 这种相关性 继为 Giles 等 ${ }^{[4]}$ 所证实. 鉴于累积的资料肯 定了这种物质与乙型肝炎而不是与甲型肝炎 的伴随关系，称其为乙型肝炎抗原 (Hepatitis B antigen, 简称 $\mathrm{HBAg}$ ) 似较上述名称和肝炎 缔合抗原 (Hepatitis-associated antigen) 更为确 切 ${ }^{[5]}$. HBAg 是否为乙型肝炎的病原目前虽 有不同的看法，但其发现对于乙型肝炎的研 究看来是一个重大的突破, 它不仅提供了乙 型肝炎最早的特异性血清学标准，而且通过
对其性质的逐步深入研究将直接弄清或有助 于弄清乙型肝炎的病原问题，本工作目的是 试图分离 $\mathrm{HBAg}$ ，以便进一步开展研究.

分离用血清系采自多次输血血友病患者 和肝炎患者，同时采用琼脂不连续对流免疫 电泳和琼脂双扩散两种方法进行。琼脂不连 续对流免度电泳法的具体步骤是: 用 $0.015 \mathrm{M}$ 巴比妥钠-盐酸缓冲液 ( $\mathrm{pH} 8.4$ ) 配制 $1 \%$ 琼 脂. 于 $7 \times 10$ 厘米的玻板上倾覆上述琼脂一 层, 厚约 3 毫米, 凝固后打孔, 孔径 2.5 毫米, 抗原孔与抗体孔边缘距离 4.5 毫米, 孔底用少 量琼脂封闭. 血清加量每孔 10 微升, 琼脂板 通过沾纸或纱布与盛有 $0.075 \mathrm{M}$ 巴比安钠盐酸缓冲液 ( $\mathrm{pH}$ 8.4) 的电极槽连接. 电泳时, 抗体孔端接正极，抗原孔端接负极。电压每 厘米 5 伏左右, 60 -90 分钟观察结果. 琼脂

表 1 琼脂不连续对流兔疫电泳和琼脂双扩散检测 $\mathrm{HBA}$ 结果的比较

\begin{tabular}{|c|c|c|c|c|c|}
\hline 血 清 编 号 & $\begin{array}{l}\text { 不连续对流 } \\
\text { 兔度泳 }\end{array}$ & 双扩散 ** & 血 清 编 号 & $\begin{array}{l}\text { 不连续对流 } \\
\text { 免度电永 }{ }^{*}\end{array}$ & 双扩散 ** \\
\hline $1-7207014-24$ & + & + & $1-720807-33$ & $t$ & - \\
\hline $1-7207018-4$ & + & 一 & $1-720708-3$ & + & - \\
\hline $1-7207021-14$ & + & - & $9-7207018-2$ & + & + \\
\hline $1-7207022-5$ & + & - & $9-7207018-14$ & + & - \\
\hline $1-7207024-4$ & + & - & $9-7207019-2$ & + & + \\
\hline $1-7207026-26$ & + & - & $9-7207019-14$ & + & - \\
\hline $1-720802-25$ & + & + & $9-7207019-41$ & + & - \\
\hline $1-720803-992$ & + & - & $9-7207020-1$ & + & - \\
\hline $1-720807-3$ & + & + & $9-7207029-4$ & + & - \\
\hline $1-720807-8$ & + & - & $9-7207029-6$ & + & - \\
\hline
\end{tabular}

* 部分试验琼脂板和电极槽绕冲液浓度分别为 $0.02 \mathrm{M}$ 和 $0.1 \mathrm{M}$.

** 部分试验琼脂加有鱼精蛋白硫酸盐,最终浓度为 1 毫克/毫升.

本文 1973 年 6 月 4 日收到。 
双扩散法则按常规进行，但配制琼脂系用加 有氯化钠 $(0.1 \mathrm{M})$ 、乙二胺四醋酸二钠 $(0.001 \mathrm{M})$ 的 $0.01 \mathrm{M}$ 三羟甲基氨基甲烷缓冲液( $\mathrm{pH} 7.6$ ). 结果从一名血友病患者血清中获得了乙型 肝炎抗原的抗体 ( $\mathrm{HBAb}$ ), 抗原检测情况见 表 1 .

表 1 仅列举不连续对流免度电泳阳性结 果与双扩散结果之比较. 可以看出, 不连续 对流免疫电泳较双扩散的检出率为高, 且在 试验过程中，未观察到双扩散阳性样品而不 连续对流免度电泳呈现阴性之情况。因此, 采 用不连续对流免疫电泳法分离 $\mathrm{HBAg}$ ，较双 扩散法获得成功的可能性要大.

$\mathrm{HBAg}$-阳性血清免度电泳分析(图 1 )结 果表明 $\mathrm{HBAg}$-阳性血清与 $\mathrm{HBAb}$ 形成特异 的沉淀弧, 而正常人血清与 HBAb 无反应, 沉 淀弧的位置与 $\alpha_{2}$ 区域相当 ${ }^{[6.7]}$. 苏丹黑染色, 呈微弱反应, 表明含有少量脂肪 ${ }^{[6]}$.

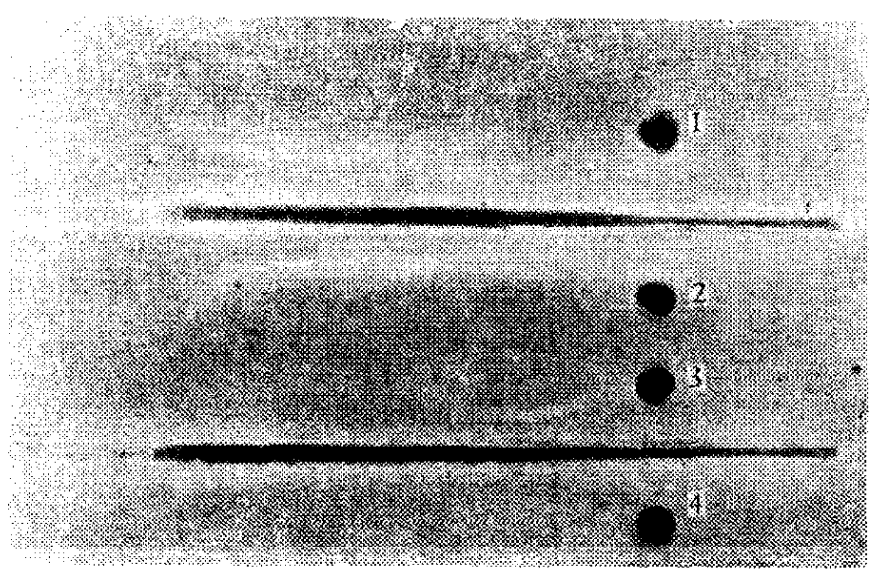

图 1 HBAg 免度电泳分析

$1 \%$ 琼脂, $0.025 \mathrm{M}$ 巴比罗钠-盐酸缓冲液, $\mathrm{pH} 8.2$, 约 5 伏/厘米. 孔 1,3 为 $\mathrm{HBAg}$-阳性血清; 孔 2,4 为 正常人血清. 显形用 (自上而下) 兔抗正常人抗血清, 䀠鼠 UBAb

HBAg 电子显微镜观察采用两种样品, 一为抗原-抗体复合物, 一为胃酶处理经超离 心后之部分提纯 HBAg. 待检样品滴加入覆 有聚乙烯甲醛一碳膜的铜网上, 用双蒸水适当 冲洗, 吸干后用 $1 \%$ 磷铇酸 $(\mathrm{pH} 7)$ 染色, 移除 多余染液, 待干, 置 Hu-11A 电子显微镜下观
察. 通过电子显微镜检查可以看到样品中有 三种主要类型的粒子 ${ }^{[8-11]}$. 近似球形的粒子 数目较多, 直径约为 $16-23$ 毫微米; 长形粒 子为数较少, 长度不一, 直径约为 20 毫微米, 在一端或两端可见有泡样膨大部分; 大粒子 为数极少,直径约为 42 毫微米 (图 2 ).
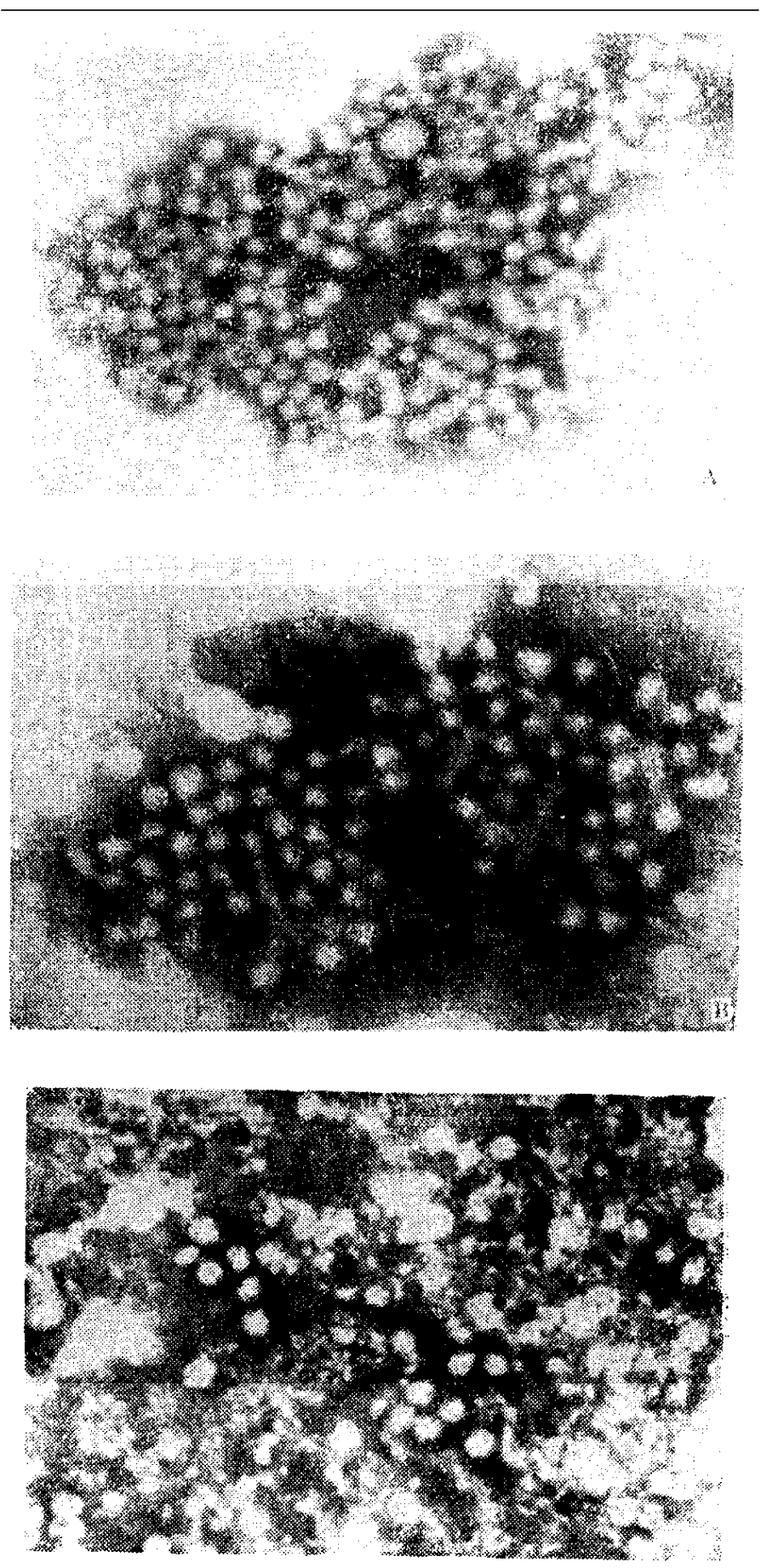

图 $2 \mathrm{HBAg}_{\mathrm{g}}$ 电子显微镜照片
A. 抗原一抗体复合物， $\times 150,000 ; B$. 抗原一抗体复 合物, $\times 200,000 ; C . H B A g, \times 150,000$ 
采用琼脂不连续对流免疫电泳和琼脂双 扩散从肝炎患者血清和多次输血血友病患者 血清中检得乙型肝炎抗原及其抗体，前者免 度电泳分析、着色反应、电子显微镜观察显示 乙型肝炎抗原的已知特征.

致谢：本工作承武钢职工医院、武汉市第九 医院、第二医院提供血清; 上海第一医学院拍摄电镜 炤片, 在此一并致谢.

\section{考文献}

[1] Blumberg, B. S., Bull. N. Y. Acad. Med., 40 (1964), 377.

[2] Prince, A. M., Proc. Natl. Acad. Sci. D.S.A., 60 (1968), 814.
[ 3 ] Prince, A. M., Lancet, II (1968), 462.

[4] Giles, J. P., MeCollum, R. W., Berndtson, I. W., Jr. and Krugman, S., New Engl. J. Med., 281 (1969), 119.

[5] 'Krugman, 8., Amer. J. Dis. Child., 123 (1972), 435.

[6] Alter, H. J. and Blumberg, B. S., Blood, 27 (1966), 297.

[7] Portocala, R., Popa, L. M., Repanovici, R., Acta. Virologica, 16 (1972), 191.

[ 8 ] Bayer, M. E., Blumberg, B. S. and Werner, B., Nature, 218 (1968), 1057.

[9] Almeida, J. D. and Waterson, A. P., Advan. Virus Res., 15 (1969), 307.

[10] Dane, D. S., Cameron, C. H. and Briggs, M., Lancet, 1 (1970), 695.

[11] Jokelainen, P. T., Krohn, K., Prince, A. M. and Finlayson, N. D. C., J. Virol., 6 (1970), 685. 